\title{
DIREITOS HUMANOS VERSUS DIREITO PENAL DO INIMIGO: É POSSÍVEL NEGAR A DIGNIDADE HUMANA?
}

\section{Marcos Leite Garcia*}

\section{Resumo:}

O presente texto tem como objetivo analisar a dicotomia entre o Direito Penal do Inimigo e os Direitos Humanos, levando-se em consideração a igualdade dos seres humanos quanto à dignidade. A dignidade da pessoa humana trata-se de um dos pilares teóricos do direito contemporâneo, junto com a liberdade, a igualdade e a fraternidade. O método utilizado para a investigação é o Dedutivo. Ao final do artigo, verifica-se que a Dignidade deve ser igual para todos os seres humanos, assim o Direito Penal do Inimigo é contrário aos mais elementares pilares dos Direitos Humanos.

Palavras-chave: Dignidade; Direito Penal do Inimigo; Direitos Humanos; Igualdade; Dicotomia.

\section{HUMAN RIGHTS VERSUS ENEMY CRIMINAL LAW: IS IT POSSIBLE TO DENY HUMAN DIGNITY?}

\begin{abstract}
This text aims to analyze the dichotomy between the Enemy Criminal Law and Human Rights, taking into account the equality of human beings in relation to dignity. The dignity of the human person is one of the theoretical pillars of contemporary law, together with freedom, equality and fraternity. The method used for the investigation is deductive. At the end of the article, it turns out that Dignity must be equal for all human beings, so the Enemy Criminal Law is contrary to the most elementary pillars of human rights.
\end{abstract}

Keywords: Dignity; Enemy Criminal Law; Human Rights; Equality; Dichotomy.

\section{Introdução}

O presente trabalho tem como objetivo teórico demonstrar o absurdo da dicotomia que defende a teoria do Direito penal do inimigo, do alemão Günther Jakobs, no sentido de que na sociedade contemporânea existem dois tipos de cidadãos: o cidadão e o não-cidadão. $\mathrm{O}$

\footnotetext{
* Doutor em Direito (2000); Master em Direitos Humanos (1990); ambos cursos realizados no Instituto de Direitos Humanos da Universidade Complutense de Madrid, Espanha. Realizou estágio pós-doutoral na Universidade de Santa Catarina entre 2011e 2012. Desde 2001 professor do Programa de Pós-Graduação Stricto Sensu em Ciência Jurídica, Cursos de Mestrado e Doutorado, e do Curso de Graduação em Direito da Universidade do Vale do Itajaí (UNIVALI)- Santa Catarina. Da mesma maneira, desde 2015 professor do Programa de Pós-Graduação em Direito, Curso de Mestrado, da Universidade de Passo Fundo (UPF) - Rio Grande do Sul.E-mail: mleitegarcia@terra.com.br
} 
primeiro titular de dignidade da pessoa humana, e assim considerado uma pessoa; e o segundo não-cidadão e não acatado como titular da dignidade da pessoa humana e por isso considerado não-pessoa.

A questão/problema é a seguinte: é possível negar a condição de persona a um ser humano? Sim ou não? Ou ainda: é possível negar a dignidade humana, relativizando a cidadania e sua condição de pessoa?

Serão os autores Bertrand Binoche (2009), professor de Sorbonne de Paris, o original de sua obra aqui aludida "Critiques des droits de l'homme" é de 1989, e posteriormente Gregorio Peces-Barba (1995, p. 39-98), os teóricos a desenvolver sólidos estudos sobre as teorias negadoras dos Direitos Humanos. Dentre as teorias negadoras dos direitos, sem nenhuma duvida, nas últimas décadas podem-se acrescentar algumas. Entre elas as variações atuais da negação típica dos conservadores, que nunca aceitaram as conquistas humanas civilizatórias da modernidade e da contemporaneidade, como o constitucionalismo do pósguerra construído sobre os pilares de um sistema jurídico baseado nos direitos humanos e na dignidade da pessoa humana. No rol das teorias negadoras e conspiradoras contra os Direitos Humanos poder-se-ia incluir a aludida por José Adércio Leite Sampaio (2004, p. 37-38) como a teoria negadora dos Direitos Humanos tipicamente brasileira ${ }^{1}$, que reduz os Direitos Humanos a uma mera proteção de delinquentes. Da mesma forma nessa lista poderia estar a doutrina das ditaduras dos tempos de guerra fria, a falaciosa doutrina da segurança nacional ${ }^{2}$;

\footnotetext{
${ }^{1}$ Certamente que entre elas está a que José Adércio Leite Sampaio (2004, p. 37) chama de teoria negadora tipicamente brasileira. Essa é a que está estruturada em bases menos sólidas e que simploriamente reduz os direitos humanos como proteção da delinquência. Dita negação dos Direitos Humanos não seria importante se não fosse o fato de fazer parte de campanhas eleitorais de políticos conservadores na atualidade, já que nos últimos tempos que em diversas oportunidades faz-se o uso de refrão contrario aos direitos humanos: "bandido bom é bandido morto" e assim como repetidamente tem-se ouvido promessas de dar carta branca aos policiais para matarem.
}

${ }^{2}$ A chamada Doutrina de Segurança Nacional se inspirava na guerra contrarrevolucionaria, tendo entre seus antecedentes as mesmas teorias nazistas, que influenciaram os movimentos contrainsurgentes e antirrevolucionários dos Estados Unidos da América, na época da guerra fria, para assim manter sua hegemonia em suas zonas de influência; também na França foram desenvolvidas suas teorias na repressão aos movimentos que buscavam a independência da Argélia. A guerra de independência da Argélia serviu de laboratório dessa doutrina negadora de direitos humanos para depois ser aplicada na América Latina. Para atingir seus objetivos se praticava a tortura, o desaparecimento forçado de pessoas e as execuções sumárias, extrajudiciais e arbitrárias em uma suposta "guerra suja", uma guerra não declarada que servia para instituir e justificar em bases nada sólidas o terrorismo de Estado. Segundo o Padre Joseph Comblin (1978) a Doutrina de Segurança Nacional apresentava como conceitos básicos a geopolítica, a bipolaridade e também a Guerra Total. A geopolítica era considerada a mais importante segundo o padre belga radicado no Brasil, já que fornecia à doutrina uma vestimenta ideológica e se justificava como ciência, claro que era na opinião de Comblin umas justificativas pseudocientíficas baseadas em ideias conservadoras, reacionárias e nacionalistas. O padre Comblin foi um 
doutrina que foi uma cínica "tentativa de justificativa" de infundadas violações sistemáticas de Direitos Humanos no continente americano, a partir da prática de terrorismo de Estado, por parte de ferrenhas ditaduras em nome da segurança nacional. Certamente tratam-se de duas injustificáveis negações dos direitos humanos: a que na prática faz com que policiais assassinem delinquentes para "fugir" do sistema de direitos humanos que protege o "bandido", a tipicamente brasileira; e a da doutrina de segurança nacional que levou ao continente americano as execuções arbitrarias, desaparecimento de pessoas e torturas como práticas sistemáticas do Estado, quando as sociedades queriam apenas melhorar as condições de vida dos menos favorecidos com a instituição de políticas públicas sociais. Ambas ideias construídas em bases teóricas pouco sólidas, mas violadores da dignidade da pessoa humana e mais ligadas à realidade de países como os da América Latina. De essa maneira, pode-se afirmar que doutrina do Direito penal do inimigo, mesmo que venha da Alemanha atual, e por isso com tintes mais sofisticados (pelo menos na aparência) ${ }^{3}$, ainda assim pode ser acrescentada no rol das teorias negadoras dos Direitos Humanos.

A emblemática obra do professor Peces-Barba que traz seu estudo sobre as teorias negadoras é de 1995, mas nela o professor já faz o prognóstico de que as teorias liberais, para o nosso tempo e desde a obra de Friedrich August von Hayek (1990) ${ }^{4}$ : a teoria conhecida como neoliberal, é e será a mais importante na hora de reduzir e negar o rol dos direitos humanos. Assim segundo Peces-Barba as teorias neoliberais são as que mais danos trazem aos direitos fundamentais no momento (texto de 1995) e no futuro. Não cabe dúvida que é acertado o prognóstico do professor madrilenho e que cada vez mais os mais atentos

importante teólogo da Teoria da Libertação e seu citado livro (1978) é recomendável para estudar a Doutrina da Segurança Nacional.

\footnotetext{
3 A ironia se deve aos argutos argumentos de Eugenio Raúl Zaffaroni (2015, p. 115) quando faz alusão aos Direitos sociais primeiramente previstos na Constituição Mexicana de 1917, fruto da Revolução de 1910, somente tiveram repercussão mundial posteriormente a partir da Constituição da Alemanha de 1919. Entre Querétaro e Weimar, diz o autor argentino que o constitucionalismo social pioneiro positivado pela Constituição de Querétaro em 1917 foi ridicularizado pelos intelectuais de seu tempo, e somente foi aceito e respeitado a partir que a Constituição de Weimar de 1919, portanto dois anos mais tarde, adotou os mesmos direitos. Por tanto foi a partir do respeito que se tem pela Europa que outras constituições, como por exemplo a Republicana da Espanha de 1931 e a brasileira de 1934, foram incorporando os direitos sociais fundamentais. Preconceito colonial contra os colonizados?

${ }^{4}$ A obra escrita originalmente em 1944, O caminho da servidão, certamente que é sua obra mais famosa de Hayek. Da mesma maneira veja-se sobre Hayek e os neoliberais do século XX a interessante interpretação do professor Antonio Enrique Pérez Luño (1986, p. 142-156) sobre a relação entre neoliberalismo e direitos humanos, trata-se junto com a de Peces-Barba de uma visão crítica sobre a negação liberal dos direitos fundamentais sociais. Ademais sobre um panorama do desenvolvimento das ideias do liberalismo, veja-se: Merquior (2014).
} 
intérpretes de nosso tempo reafirmam os signos negativos de nossa era de globalização neoliberal (como por exemplo os seguintes autores: Bauman, 2008; Castells, 2012; Morin, 2013; Chomsky, 2017; Giddens, 2003; Zizek, 2011; Ulrich Beck, 2011; Hartmut Rosa, 2016; entre outros). Entre eles as negações do conceito de pessoa, da dignidade da pessoa humana fazem com que o Direito penal do inimigo seja evidentemente uma teoria negadora dos Direitos Humanos do século XXI e concordamos com a crítica que estão vinculadas com as elites que desejam controlar a todos e a todas as forças que saem do controle.

O método utilizado para a Fase de Investigação e o Relato de Pesquisa será o Dedutivo $^{5}$, cuja premissa maior são as reivindicações históricas pela igualdade entre os seres humanos, sua posterior consolidação e o consenso estipulado nas constituições democráticas contemporâneas e nos documentos internacionais de proteção dos Direitos Humanos. As técnicas selecionadas ao cumprimento do método eleito são a Pesquisa Bibliográfica e Documental, a Categoria e o Conceito Operacional, quando necessários (Pasold, 2018, respectivamente p. $215,217,207)$.

\section{A dignidade da pessoa humana e o direito penal do inimigo}

Para determinar o caminho filosófico percorrido pela dignidade da pessoa humana como ponto de partida e ponto de chegada dos direitos fundamentais, Gregorio Peces-Barba chama a atenção para os ensinamentos da história. Em escrito sobre o tema, o autor madrilenho nos faz lembrar que "a ideia de dignidade, como todos os demais que tratamos no âmbito da cultura moral, política e jurídica, são construções do pensamento humano" (PecesBarba, 1994, p. 319) ${ }^{6}$. Nossa interpretação no que o professor Gregorio Peces-Barba quer dizer, sobre a dignidade humana ser o ponto de partida e ao mesmo tempo o ponto chegada dos direitos humanos, significa que: $1^{\circ}$ ) A dignidade da pessoa humana deve ser teoricamente considerada como fundamento dos direitos humanos, desde a igualdade; e por isso seu ponto de partida; $2^{\circ}$ ) A dignidade da pessoa humana deve ser averiguada na prática para ver se houve uma violação de direitos humanos, desde a igualdade; enfim, se foi violado um direito fundamental, deve-se ver se foi violada a dignidade da pessoa humana; e por isso, depois de um longo caminho filosófico teórico e prático, o ponto de chegada dos direitos humanos.

\footnotetext{
5 “ “...] base lógica da dinâmica da Pesquisa Científica que consiste em estabelecer uma formulação geral e, em seguida, buscar as partes do fenômeno de modo a sustentar a formulação geral". (PASOLD, 2018, p. 215).

${ }^{6}$ As traduções dos textos do espanhol para o português são de responsabilidade do autor do presente artigo.
} 
Em toda sua obra Gregorio Peces-Barba (1994; 1995 e 2003) destaca que a triste realidade dos direitos humanos - e seu fundamento: a dignidade da pessoa humana - sofreram ataques na sua essência e isso desde sempre. A dignidade teve que superar ataques históricos e confrontações doutrinárias para iniciar o que Peces-Barba chama de "processo de humanização e de racionalização", que irão acompanhar a pessoa humana no desenvolvimento de sua dignidade e a sociedade nos diversos esforços da liberação democrática (Peces-Barba, 2003, p. 66). E pelo que se pode ver, os direitos humanos seguem sofrendo ataques na atualidade. Na concepção positivista ética de Peces-Barba (2003, p. $67-$ 68) a dignidade da pessoa humana é um conceito pré-político e pré-jurídico, ainda que com vocação de ser assumido pelo poder e passar a integrar o ordenamento jurídico.

Assim, os tratados internacionais e as constituições nacionais consagram a dignidade da pessoa humana, sendo proclamada como princípio e norma integrante do mais alto patamar hierárquico dos sistemas jurídicos. A dignidade é destacada praticamente em todas as declarações e tratados internacionais sobre direitos humanos, e está consagrada em pelo menos 149 constituições vigentes em suas respectivas nações (Sarmento, 2016, p. 15), ainda que a questão de sua efetividade seja outra questão bastante mais complexa ${ }^{7}$. Ainda que na maioria dos casos a realidade social não está de acordo com o que está escrito nas constituições, mesmo que tenha a dignidade humana previstas expressamente, quando ao contrário as mesmas servem apenas como uma simples folha de papel, no dizer de Ferdinand Lassalle (1998) - em seu clássico de 1864 -, ou mesmo como uma constituição simbólica, no dizer de Marcello Neves (2007). Em sentido contrário, importante recordar também que sua vigência é reconhecida pela jurisprudência em países que não contêm a dignidade da pessoa humana expressamente em suas constituições, como por exemplo na França e nos Estados Unidos da América (Sarmento, 2016, p. 15). Da mesma maneira, as cortes e tribunais internacionais tornaram a dignidade como parâmetro de defesa dos direitos humanos ${ }^{8}$, assim

\footnotetext{
${ }^{7}$ Assim entre os citados 149 países que expressamente consagram a dignidade estão incluídos verdadeiras ditaduras e regimes de exceção donde não há igualdade, liberdade e justiça imparcial. A hipocrisia é um terrível característica humana e em muitos países usam a dignidade humana apenas como demagogia. Assim encontramos a consagração da dignidade humana em países notórios pelas graves violação dos direitos humanos como a Síria de Al Bashar, Sudão e Somália, entre muitos outros em todo o mundo (entre os quais poderíamos citar diversos países da América Latina, até mesmo o Brasil pela situação de extrema pobreza de boa parte de sua população).

${ }^{8}$ Muitíssimos são os casos em que dignidade é considerada nos tribunais internacionais, assim como também muitas são as ações da Comunidade Internacional para zelar pela dignidade da pessoa humana. Por exemplo, o Índice de Desenvolvimento Humano (IDH) elaborado anualmente pelo Programa das Nações Unidas para o Desenvolvimento (PNUD), criado em 1990 pelos economistas Amartya Sen e Mahbub ul Hag, além de servir
} 
como também a jurisprudência dos tribunais e das supremas cortes de distintos países considerados como democráticos. Uma vez que como preconiza Boaventura de Souza Santos (2011, p. 125): “(...) sem direitos de cidadania efetivos a democracia é uma ditadura mal disfarçada". Assim, a dignidade humana é o fundamento de todos os direitos humanos. E sem proteção da dignidade não há efetivamente proteção dos direitos humanos. E sem a efetiva proteção e o vigor de uma cultura e mentalidade a favor dos direitos humanos, simplesmente não há democracia.

Na Alemanha do segundo pós-guerra, a Lei Fundamental de Bonn de 1949 será a primeira constituição a consagrar a Dignidade Humana como norma constitucional e princípio que rege todo o sistema ${ }^{9}$. As sociedades que viveram ditaduras sanguinárias, a exemplo das tristes experiência do nazi-fascismo, acabaram por consagrar em seus processos de redemocratização a dignidade humana dentre os seus fundamentos e princípios de forma expressa. As constituições de Portugal de 1976 (art. 1º) e da Espanha 1978 (art. 10) também consagram a dignidade humana em seus ordenamentos. Na Constituição brasileira de 1988 a dignidade da pessoa humana é consagrada como fundamento da República em art. $1^{\text {o }}$, III. O constitucionalista brasileiro Paulo Bonavides (2014, p. 15) aponta que se trata de "norma das normas dos direitos fundamentais". A norma que dá fundamento a todos os direitos fundamentais consagrados na Constituição Republicana de 1988. O autor brasileiro Ingo Wolfgang Sarlet (2001, p. 60), categoricamente, define a dignidade da pessoa humana como:

(...) a qualidade intrínseca e distintiva de cada ser humano que o faz merecedor do mesmo respeito e consideração por parte do Estado e da comunidade, implicando, neste sentido, um complexo de direitos e deveres fundamentais que assegurem a pessoa tanto contra todo e qualquer ato de cunho degradante e desumano, como venham a lhe garantir as condições existenciais mínimas para uma vida saudável, além de propiciar e promover sua participação ativa e corresponsável nos destinos da própria existência e da vida em comunhão com os demais seres humanos.

No mesmo sentido lecionava o professor Jesus González Amuchastegui (2004, p. 421), a dignidade é inerente e a possuem todos os seres humanos, igual e essencialmente, com

para medir o desenvolvimento social de um país, a qualidade de vida de um povo, traduz e tem servido também para averiguar a questão da dignidade humana em uma determinada sociedade. Não é por casualidade que a República Federativa do Brasil obtém a cada ano um número baixo do IDH para as suas possibilidades e potencial, sendo que dos 189 países avaliados é o número 79 do Relatório do PNUD de 2017, já que possuiu baixos índices de dignidade da pessoa humana dos excluídos (educação, expectativa de vida e renda).

9 A Lei Fundamental de Bonn, que é o nome utilizado para designar a Constituição da República Federal da Alemanha, aprovada em 22 de maio de 1949, em seu primeiro artigo já consagra a dignidade da pessoa humana e os direitos fundamentais: "1. A dignidade da pessoa humana é intangível. Respeitá-la e protegê-la é obrigação de todo o poder público. 2. O povo alemão reconhece, por isto, os direitos invioláveis e inalienáveis da pessoa humana como fundamento de toda comunidade humana, da paz e da justiça no mundo". 
independência de seus méritos e capacidades, ou de quaisquer outros traços contíguos que nos caracterizam. Por essa razão que nós, os seres humanos, argumenta o professor González Amuchastegui (2004, p. 422), em fundamental livro sobre o tema, no sentido de que não somos uma mercadoria a que se assigna um preço - invocando a concepção de Kant - ou que podemos ser substituídos por algo equivalente valor. $\mathrm{O}$ ser humano não tem preço, ao contrário, é titular de dignidade, assim é a clássica lição de Immanuel Kant na Fundamentação da metafísica dos costumes (1984) publicada no ano de 1785. Ademais, acrescenta o professor Amuchastegui (2004, p. 422), que nossa condição kantiana de seres dignos não deriva de nosso comportamento ("de nuestra adopción de comportamientos virtuosos"), e por paradoxal que possa parecer, "preservamos nuestra dignidad con independiencia de lo indigno que podamos llegar a ser". Argumenta ainda o professor Amuchastegui, infelizmente precocemente falecido, baseado em Alan Gewirth (1992, p. $15)^{10}$, que a consequência dessa igualdade perante à dignidade é que ela constitui uma característica que todos por igual compartilham sejam criminosos ou santos, heróis ou covardes, sábios ou idiotas, proletários ou patrões, mendigos indigentes ou capitalistas opulentos, deficientes mentais ou pessoas sem deficiência, atletas ou pessoas sedentárias, progressistas libertários de esquerda ou conservadores reacionários de direita etc.

A dignidade da pessoa humana então é tratada na Constituição brasileira de 1988 como um fundamento da República que tem como objetivo proteger, preservar e cuidar do indivíduo, assim claramente dispõe: a todos os membros da sociedade. Uma vez que a dignidade acompanha a pessoa durante toda a sua vida, assim não podendo, em nenhuma hipótese, ser-lhe retirada, pois está na essência de sua própria natureza humana, não sendo admitido que o ser humano seja vítima de qualquer tipo de discriminação, humilhação e agressão (física ou moral), bem como ser perseguido, torturado, maltratado, vilipendiado ou mesmo ameaçado. Nesse sentido, a definição de Sarlet e a lição do professor espanhol González Amuchastegui, demonstram que a dignidade, além de irrenunciável e inalienável, na medida em que constitui elemento que qualifica o ser humano, não pode ser dela afastado, ou seja, a dignidade não pode ser negada em nenhuma circunstância. Então ainda, segundo Sarlet (2001, p. 100-101), “(...) a dignidade independe das circunstancias concretas, sendo algo

\footnotetext{
${ }^{10}$ GEWIRTH, Alan. "Human Rigth as the basis of rigths". In: MEYER, Michel J. and PARENT, William A. (eds.). The Constitution of Rights. Human dignity and american values. Cornell University Press Ithaca and London, 1992. p. 15. Apud: González Amuchastegui, 2004, p. 422.
} 
inerente a toda e qualquer pessoa humana, de tal sorte que todos - mesmo o maior dos criminosos - são iguais em dignidade".

Da mesma forma o outro autor brasileiro que trata com maestria a questão da dignidade da pessoa humana, Daniel Sarmento (2016, p. 104) leciona que:

No Direito contemporâneo a palavra 'dignidade' tem sido usada (...) geralmente associado aos direitos humanos. A palavra dignidade é empregada como qualidade intrínseca de todos os seres humanos, independentemente de seu status e de sua conduta. A dignidade é ontológica, e não contingente. Em outras palavras, todos os indivíduos que pertencem à espécie humana possuem dignidade apenas por serem pessoas (Grifos no original).

E também destaca Daniel Sarmento (2016, p. 104) no sentido da igualdade existente na questão da dignidade da pessoa humana:

Não se admitem restrições relativas a fatores de gênero, idade, cor, orientação sexual, nacionalidade, deficiência, capacidade intelectual ou qualquer outro. E ninguém se despe de dignidade humana, ainda que cometa crimes gravíssimos, que pratique os atos mais abomináveis. O homicida e o torturador têm o mesmo valor intrínseco que o herói e que o santo. A dignidade humana, que não é concedida por ninguém, não pode ser retirada pelo Estado ou pela sociedade, em nenhuma situação. Ela é inerente à personalidade humana e, portanto, embora possa ser violada e ofendida pela ação do Estado ou de particulares, jamais será perdida pelo seu titular.

Será o jusfilósofo italiano Norberto Bobbio (1992, p. 26) quem consagra a Declaração Universal de Direitos Humanos como a solução do fundamento dos Direitos Humanos: “A Declaração Universal dos Direitos do Humanos representa a manifestação da única prova através da qual um sistema de valores pode ser considerado humanamente fundado e, portanto, reconhecido: e essa prova é o consenso geral acerca de sua validade". Em duas direcionadas passagens a Declaração de 1948 trata da dignidade da pessoa humana e assim faz ênfase da igualdade, em seu preâmbulo e no artigo $1^{\circ}$ :

Considerando que o reconhecimento da dignidade inerente a todos os membros da família humana e de seus direitos iguais e inalienáveis é o fundamento da liberdade, da justiça e da paz no mundo;

Artigo $1^{\circ}$ :

Todos os seres humanos nascem livres e iguais em dignidade e direitos. São dotados de razão e consciência e devem agir em relação uns aos outros com espírito de fraternidade. (grifos acrescentados).

Assim fica bem claro que a Comunidade Internacional, a partir da Declaração Universal de 1948, considera a dignidade igual para todas as pessoas, e como o fundamento da liberdade, da justiça e da paz no mundo. Essa paz é também a paz social e deve ser considerado o não uso do direito penal como controle social. Assim a cidadania e os direitos 
fundamentais devem ser considerados para todas as pessoas. Infelizmente, o título de cidadão acaba sendo o último privilégio de nossa era. A crítica de Ferrajoli ao atual conceito de cidadania é importante ser abordada no contexto do presente artigo.

Em seu clássico ensaio Cidadania e classe social Thomas Marshall expõe uma tipologia de direitos fundamentais que pertencem à cidadania, os quais estão classificados em três categorias: direitos civis, políticos e sociais (Marshall, 1998). Em esta obra Marshall define a cidadania ${ }^{11}$ como a possessão de direitos e o fato de pertencer a uma comunidade determinada.

Sobre a questão em contraposição à noção de Thomas Marshall, Luigi Ferrajoli (1999, p. 98) propõe uma concepção de direitos fundamentais supranacionais desde uma visão sóciojurídica e historiográfica. Assim sua crítica a Marshall é no contexto da incomensurabilidade ou incomunicabilidade entre os estudos jurídicos e sociológicos em matéria de cidadania, o que deixa sua noção de direitos fundamentais divididos em civis, políticos e sociais aos que pertencem à determinada comunidade, sem os necessários aportes dos estudos filosóficos e sociológicos para uma análise realista do grau de efetividade dos direitos e as condições econômicas, políticas e sociais de sua garantia. Exatamente nesse contexto Ferrajoli expõe que os processos de globalização, integração mundial e fenômenos migratórios - que existem desde sempre, mas que foram acirrados nos últimos tempos -, colocaram em contradição a teoria de Marshall e dos defensores dos direitos da pessoa como cidadão na atualidade. De tal forma que, o jusfilósofo italiano de Florença propõe superar esta contradição mediante a uma verdadeira internacionalização dos direitos fundamentais, eliminando essa diferenciação, ao passar do status civitatis ao status personae.

Assim propõe Ferrajoli a mudança de postura da teoria dos direitos fundamentais para que na prática seja efetivamente garantidos os direitos e a dignidade de todas as pessoas humanas, já que para ele a cidadania, como está vista na atualidade e desde Marshall, representa o último privilégio do status (como os privilégios de estamentos de outrora), e também o último fator de exclusão e de discriminação (preconceitos, aporofóbias e xenofobias legalizados), o último resíduo pré-moderno da desigualdade pessoal em contraposição à proclamada universalidade e igualdade dos direitos humanos (art. $1^{\circ}$ da

\footnotetext{
${ }^{11}$ A noção de Marshall (1998) de cidadania se inscreve na tradição republicana que tem como antecedentes a ética publicista de Aristóteles, Maquiavel e Rousseau. A construção da cidadania teria percorrido três etapas históricas: os direitos civis do século XVIII, os direitos políticos do século XIX e em último estágio os direitos sociais positivado nas constituições a partir de Querétaro em 1917 e Weimar em 1919.
} 
Declaração Universal de 1948). A cidadania seria o último "muro" contra a universalidade dos direitos humanos e da dignidade da pessoa humana.

Comentando sobre a crise atual do Estado e da comunidade vista somente como nacional que caracteriza o novo milênio, conectada com fenômenos atualíssimos como o crescimento do neonazismo e da popularidade das demagogias da extrema direita em diversos países, assim como fenômenos como os conflitos étnicos, as migrações em massa e cada vez mais o acirramento das diferenças entre ricos e pobres (numa sociedade de globalização liberal e de opinião única, cada vez menos democrática na qual o povo está cada vez mais longe do poder e dos centros de decisões), Ferrajoli (1999) propõe que é necessário reconhecer a cidadania já não como origem estatal e sim como um fator de inclusão e igualdade. Os direitos se converteram em direitos de cidadania exclusivos e de privilegiados a partir do momento em que se tratou coloca-los intramuros, os direitos fundamentais devem ser de toda a família humana ${ }^{12}$.

Assim, Luigi Ferrajoli deixa claro a necessidade de levar a cabo um verdadeiro processo de internacionalização dos direitos humanos e que a pretensão de universalidade dos mesmos deve deixar de ser apenas uma intenção e passar a ser efetiva para assim poder ser garantido os direitos de todos os seres humanos. A universalização dos Direitos Humanos significa a universalização da dignidade da pessoa humana.

A crítica da doutrina atual do Direito penal é no sentido de que a consagração da dignidade da pessoa humana foi colocada em xeque mate pela doutrina do Direito penal do inimigo. Algo como a questão do não-cidadão anteriormente apontado por Luigi Ferrajoli como crítica a teoria de Thomas Marshall, ou até que essa distinção seja o início ou fundamento da atual, o autor espanhol Lima Torrado chama a atenção de como podem dizer que o inimigo é a não-pessoa.

\section{A dicotomia entre o ser humano considerado pessoa e o não considerado como uma pessoa}

\footnotetext{
12 Dessa maneira expõe Ferrajoli (1999, p. 117) que na atualidade, no atual século XXI levar os direitos fundamentais a sério significa: "(...) tener el valor de desvincularlos de la ciudadanía como pertenencia (a uma comunidade estatal determinada) y de su carácter estatal. Desvincularlos de la ciudadanía significa entonces reconocer el carácter supraestatal - en los sentidos de una doble garantía constitucional e internacional - y por tanto tutelarlos no sólo dentro sino también fuera y frente a los Estados, poniendo fin a este gran apartheid que excluye de su disfrute a la mayoría del género humano, contradiciendo su proclamado universalismo".
} 
Sobre a aludida dicotomia cidadão e não-cidadão, expostas com pretensões de ciência, acertadamente Lima Torrado a chama de pseudociência. Por um lado, a primeira categoria de seres humanos exerce a cidadania plena e tem garantidos seus direitos fundamentais; e por outro lado, a segunda categoria de seres humanos não considerada como cidadão não tem nenhuma garantia e tem os seus direitos fundamentais plenamente violados e respaldados no fato de ser perigoso, ou seja: o inimigo perigoso. Para tal conceito será o alemão Günther Jakobs que irá desenvolver uma aplicação do Direito penal de maneira excludente chocando com a base de toda a construção do Direito contemporâneo.

O estudo de Lima Torrado é legitimado e pertinente não somente por sua relevância doutrinal, mas também - como destacado por suas próprias palavras (Lima, 2009, p. 378) afeta as situações práticas no mundo real no qual as elites dominam a sociedade. Certamente que é um fato mundial de que cada vez mais vivemos em uma sociedade que é cada vez menos democrática e desigual. Diz Lima Torrado (2009, p. 278) que se a teoria nega o fundamento de um direito humano evidentemente que se abre cada vez mais a porta para sua violação. Inclusive, acrescenta, que “(...) quando na prática se produz uma violação de direitos (humanos) se está negando, ao mesmo tempo, e precisamente como consequência dessa violação, a dignidade da pessoa humana do indivíduo".

O professor da Universidad Complutense de Madrid, Jesus Lima Torrado (2009 $b$ ) aduz a sua relevante preocupação com o Direito e sua prática no atual processo de Globalização de opinião única (que como é consabido e aludido por diversos autores se trata pois na prática de um processo de globalização neoliberal que por esse motivo leva consigo elementos de violações de Direitos Humanos): "Nos últimos anos se constata o progressivo deterioro das garantias de direitos humanos que vai em paralelo ao também progressivo desenvolvimento de argumentos doutrinais de caráter nihilista e anti-humanista". Parece que não cabe dúvidas que na doutrina atual vê-se a tentativa de abrir caminhos, de forma insistente, a um perigoso processo de involução - palavras de Lima Torrado (2009 a, p. 378) - na teoria dos direitos fundamentais que está vinculada e falsamente legitimada (pseudolegitimidade) em virtude da negação do fundamento dos direitos humanos, que são os pilares básicos de nossa civilização contemporâneas. As conquistas humanas civilizatórias, traduzidas como direitos humanos e respeito à dignidade, estão sendo alvo de doutrinas que trazem consigo o que Lima Torrado chama de pseudolegitimidade da violação das garantias mais elementares que protegem a dignidade da pessoa humana. 
Exatamente no entorno de uma sociedade como a brasileira que tem sérias dificuldades com a aceitação pacífica do conceito de igualdade - sobretudo a partir de abismais desigualdades sociais - o texto do professor da Universidade Complutense de Madrid é de fundamental importância. O sociólogo brasileiro Jessé Souza chama a atenção para a subcidadania $(2018$, a) que existe no Brasil, ou seja, como lecionam os professores Lênio Streck e Rosivaldo dos Santos (2013 p. 35) "em nossa sociedade existem os amigos do poder", aqueles que têm um Direito penal com todas as garantias e "os inimigos do poder", para os quais há um Direito penal de exceção num país com diferenças socais abismais ${ }^{13}$. Os autores brasileiros citados evidentemente fazem alusão a dicotomia proposta por Carl Schmitt: a do amigo-inimigo. O inimigo é assim reconhecido assim como determinado o grupo dos amigos aliados contra ele e constituindo uma relação de antagonismo entre "nós" (os amigos) e "eles" (os inimigos). A vigência desse Direito penal de exceção dá-se em um vigente Estado de Exceção ${ }^{14}$, que antes era previsto para momentos ou ocasiões especiais (revoluções, guerras civis etc) ${ }^{15}$, agora faz parte do cotidiano, mesmo nas ditas democracias ocidentais. Assim a partir do momento que vira regra, o estado de exceção se apresenta mais como técnica de governo do que medida excepcional, deixando transparecer sua "natureza de paradigma constitutivo da ordem jurídica" $" 16$.

Assim apresenta-se claramente uma subcidadania brasileira, no qual o suposto Direito penal do inimigo é seletivo com o adversário político das elites, com o excluído, ou seja, com

\footnotetext{
${ }^{13}$ Sobre a importação da teoria do direito penal do inimigo para o Brasil os citados autores comentam: "Imaginese (...) importar essa teoria para nosso país em que há uma realidade de exclusão social tremenda, indevida e indesejada contra os que vivem na margem. Cuida-se de uma interpretação inautêntica, corrompida. Talvez por isso Jakobs tenha sido tao odiado por aqui. Na verdade, ele não é o culpado, mas sim quem lhe importa sem considerar a autenticidade dos fundamentos do direito penal do inimigo em terra tupiniquins, como se existem verdades fora da tradição". (STRECK; SANTOS JR., 2013, p. 39).

${ }^{14} \mathrm{Na}$ Constituição da República Federativa do Brasil de 1988, o Estado de Exceção é regulado no Título V, sob o nome Da Defesa do Estado e das Instituições Democráticas (artigos 136 a 141), admitindo duas modalidades, o Estado de Defesa e o Estado de Sítio. De acordo com o art. 141, uma vez cessado o estado de sítio ou de defesa, cessarão também seus efeitos, sem prejuízo da responsabilidade pelos ilícitos cometidos por seus executores ou agentes.

${ }^{15}$ Segundo Zaffaroni (2011, p. 145-146) não haveria razão para confundir o Estado excepcional constitucional com uma guerra irregular ou permanente, e o perigo reside justamente no fato de que já que não sendo uma guerra em sentido convencional, acaba por não ser objeto de observação pelas organizações e normas do então chamado direito vigente nas guerras: o direito internacional humanitário.

${ }^{16}$ Para o filósofo italiano Giorgio Agamben (2004) o Estado de exceção se apresenta cada vez mais na condição de ordinário. Assim chama a atenção Agamben, o receio é o de que o estado de exceção possa se tornar cada vez mais regra e menos exceção, a ponto de se constituir em paradigma de governo nas democracias contemporâneas ocidentais.
} 
o pobre, o negro e os párias da sociedade de consumo ${ }^{17}$. Se no hemisfério norte o Direito penal do inimigo é aplicado ao suspeito de ser um terrorista, mesmo com a possibilidade de ser inocente, pois entre todas as garantias que não são observadas a presunção de inocência é a primeira a cair por terra; ao narcotraficante e ao imigrante pobre; no hemisfério sul o mesmo é aplicado aos excluídos. De todas a formas toda esse é situação é um absurdo, uma catástrofe para a humanidade, o fato de não garantir os direitos fundamentais para qualquer ser humano.

\section{A desigualdade proposta pelo Direito penal do inimigo não cabe em um Estado Democrático de Direito}

Claramente em Francisco Muñoz Conde e Eugenio Raúl Zaffaroni encontramos terminantemente que não é possível conviver com o punitivismo de um direito penal de exceção preconceituoso em um Estado democrático e constitucional de Direito. De acordo com as premissas e o desenvolvimento de um Direito Penal moderno e dentro do contexto do paradigma de um sistema de normas contemporâneo de um autêntico Estado Constitucional e Democrático de Direito, o Direito penal do inimigo - por violar princípios de direitos fundamentais como a igualdade perante a lei e a dignidade da pessoa humana - não pode nem mesmo ser considerado Direito penal. Seria algo fora do conceito, seria um direito de exceção típicos dos Estados de exceção e das piores ditaduras. Um direito seletivo e sem critérios democráticos. Quanto à nomenclatura, para Muñoz Conde (2012, p. 69) que leciona que claramente o Direito penal do inimigo não é o que se pode chamar de um autêntico Direito

\footnotetext{
${ }^{17}$ Será Bauman (2005) em Vidas desperdiçadas que irá expor sobre seres humanos tratados como resíduos na sociedade contemporânea, aqueles que não contam, os excluídos, os marginais, os invisíveis. Numa sociedade socialmente desigual alguns falam de meritocracia. Não cabe falar de igualdade de oportunidade em sociedades tão injustas. O sociólogo Jessé Souza (2018 b, p. 49) é categórico: "No mundo moderno, cuja legitimidade é baseada na liberdade e na igualdade de seus membros, o poder não se manifesta abertamente como no passado. No passado, o pertencimento à família certa e à classe social certa dava a garantia, aceita como tal pelos dominados, de que os privilégios eram "justos" porque espelhavam a "superioridade natural" dos bem-nascidos. No mundo moderno, os privilégios continuam a ser transmitidos por herança familiar e de classe (...), mas sua aceitação depende que os mesmos "apareçam", agora, não como atributo de sangue, de herança, de algo fortuito, portanto, mas como produto "natural" do "talento" especial, como "mérito" do indivíduo privilegiado. Existiria, no mundo moderno, uma "igualdade de oportunidade" que seria a forma de conciliar as demandas de igualdade e liberdade. Os privilégios que resultam disso não seriam "desigualdades fortuitas", como no passado com a dominância do status de sangue, mas "desigualdade justas" porque decorrentes do esforço e desempenho diferencial do indivíduo". Segue Jessé Souza (2018 b, p. 49) falando sobre os privilegiados: "O que assegura, portanto, a "justiça" e a legitimidade do privilégio moderno é o fato de que ele seja percebido como conquista e esforço individual. Nesse sentido, podemos falar que a ideologia principal do mundo moderno é a "meritocracia", ou seja, a ilusão, ainda que seja ilusão bem fundamentada na propaganda e na indústria cultural, de que os privilégios modernos são "justos". Sua justiça reside no fato de que "é do interesse de todos" que existam "recompensas" para indivíduos de alto desempenho em funções importantes para a reprodução da sociedade. O "privilégio" individual é legitimado na sociedade moderna e democrática, fundamentada na pressuposição de igualdade e liberdade dos indivíduos, apenas e enquanto exista essa pressuposição".
} 
penal, mas ele não vê muita importância no assunto: "Não acredito que ajude a aclarar essa reflexão, negar ao Direito penal do inimigo o caráter ou incluso o nome de Direito penal”.

Por outro lado, importante ressaltar que Muñoz Conde exemplifica que na época da ditadura fascista espanhola muitos jovens eram perseguidos pela polícia repressora do regime franquista, que além de agredir, prender e punir muitos por crimes contra o Estado (era a ditadura!) e até condenar a morte por terrorismo (últimas execuções do franquismo foi em setembro de 1975) e que agora esses mesmos são defensores do Direito penal de exceção. Na opinião de Muñoz Conde (2012, p. 71), “(...) é lamentável que alguns dos que sofreram em seus corpos os rigores desse Direito penal do inimigo não tenham agora inconveniência em admiti-lo, ao menos hipoteticamente, para outros inimigos". Ainda assim, estamos de acordo que o Direito penal do inimigo deveria ser considerado um não-direito penal pela doutrina que preza pela democracia, pela dignidade das pessoas humanas, pela igualdade, liberdade, segurança jurídica, pelas garantias de direitos fundamentais e pelos tratados internacionais de direitos humanos. Deveria a doutrina atual do Direito negar a nomenclatura de Direito penal ao chamado Direito penal do inimigo. A teoria de Günther Jakobs não é ciência nem muito menos democrática, uma vez que como ressalta nosso homenageado Lima Torrado estabelece falsos conceitos de não-pessoa, no-persona e nega a dignidade humana para seres humanos. A doutrina do inimigo, o não-pessoa e sem-direitos/garantias fundamentais, deveria ficar no mesmo patamar que outras doutrinas de exceção, como a Doutrina da Segurança Nacional, que muito dano causou aos cidadãos da América Latina nas suas respectivas e sanguinárias ditaduras. Aliás, ambas doutrinas têm muitas similitudes, uma vez que estão na mesma origem do nazismo, foram usadas por regimes ditatoriais, foram usadas nas ditaduras de América Latina e são totalmente incompatíveis com um Estado Democrático de Direito.

Assim Muñoz Conde e Zaffaroni claramente enfrentam a questão de que o Direito penal do inimigo afronta à democracia, afronta ao Estado de Direito Contemporâneo. Zaffaroni (2011, p. 18) deixa claro que leciona:

A essência do tratamento diferenciado que se atribui ao inimigo consiste em que o direito que lhe nega sua condição de pessoa. Ele só é considerado sob aspecto de ente perigoso ou daninho. Por mais que a ideia seja matizada, quando se propõe estabelecer a distinção entre cidadãos (pessoas) e inimigos (não-pessoas), faz-se referencia a seres humanos que são privados de certos direitos individuais, motivo pelo qual deixaram de ser considerados pessoas, e esta é a primeira incompatibilidade que a aceitação do hostis, no direito, apresenta com relação ao princípio do Estado de direito (grifos no original).

Segundo Zaffaroni (2011, p. 21-22), o estrangeiro (hostis alienigena) é o núcleo central que abarcará a todos os que incomodam o poder, os insubordináveis, indisciplinados 
ou simples estrangeiros, que, como estranhos, são desconhecidos e, como todo desconhecido, inspiram desconfiança e, por conseguinte, tornam-se suspeitos por serem potencialmente perigosos.

Ressalta o professor de Sevilha Francisco Muñoz Conde (2012, p. 62) que o Direito penal previsto na vigência do nazismo, tratava-se evidentemente como um regime totalitário, no qual se considerava estabelecido um direito penal preconceituoso já que previa que existisse um sistema de Direito Penal diferenciado para o "inimigo" e "os estranhos à comunidade". Da mesma maneira em outros momentos totalitários, como bem recorda Zaffaroni (2011, p. 69-82), nas ditaduras da Espanha, Itália, Portugal e mesmo nas ditaduras do cone sul Chile, Brasil, Argentina e Uruguai e muitas outras sempre esteve vigente um direito penal diferenciado para o inimigo, para o tido como diferente. Porém, como muito bem destaca Muñoz Conde (2012, p. 62) "uma distinção como essa é mais difícil de ser assumida no Estado de Direito, que, por definição, não admite que se possa distinguir entre 'cidadãos' e 'inimigos', na clássica distinção do famoso politólogo nazista Carl Schmitt), como sujeitos distintos níveis de respeito e proteção jurídica". Assim leciona categoricamente o professor de Sevilha (Ibidem) sobre as garantias fundamentais do Direito penal:

Os direitos e garantias fundamentais próprios do Estado de Direito, sobretudo as de caráter penal material (princípios de legalidade, intervenção mínima e culpabilidade) e processual penal (direito à presunção de inocência, à tutela judicial, a não fazer declarações contra si mesmo etc.), são pressupostos irrenunciáveis da própria essência do Estado de Direito.

Acrescenta-se que são os pressupostos da existência ou não de um Estado Democrático e Constitucional de Direito. Dessa maneira, Muñoz Conde (Ibidem) determina que:

(...) se se admite sua derrogação (os direitos e garantias fundamentais), ainda que seja em casos pontuais extremos e muito graves, deve-se admitir também o desmantelamento do Estado de Direito, cujo ordenamento jurídico se converte em um ordenamento puramente tecnocrata ou funcional, sem nenhuma referência a um sistema de valores ou, o que é pior, referido a qualquer sistema, ainda que injusto, sempre que seus executores tenham o poder ou a força suficiente para lhe impor.

Sobre a situação de exceção descrita Muñoz Conde (Ibidem) afirma categoricamente que: "O Direito assim entendido se converte em um mero Direito do Estado, no qual é submetido aos interesses que, em cada momento, o Estado ou as forcas que controlam ou monopolizam seu poder determinam".

Dessa forma então, para Muñoz Conde (2012, p. 6-2-63): “(...) o Direito é então simplesmente o que em cada momento convém ao Estado (ou as elites que controlam os 
poderes do Estado), que é, ao mesmo tempo, o que prejudica e acarreta o maior dano possível a seus inimigos". Para matizar a dimensão do problema, vale a comparação que segundo Muñoz Conde (2012 p. 63) os juristas mais importantes do nazismo (Roland Freisler e Hans Franck) afirmavam e formulavam ideias de maneira muito clara: "Direito é o que deve ser útil ao povo". Assim preconiza Muñoz Conde (Ibidem): "Substitua-se o termo 'povo' por 'Estado' ou por 'sistema' e o termo 'útil' por 'funcional' e teremos uma fundamentação perfeitamente funcionalista do Direito penal do inimigo". E ainda preconiza de forma categórica o catedrático de Sevilha:

A única diferença entre a fundamentação funcionalista atual do Direito penal que oferecia o
nacional-socialismo é que o funcionalismo está disposto a assumir também que Direito é
funcional (útil) ao sistema democrático, ainda que muitos de seus preceitos não tenham nada de
democráticos.

Dessa maneira, resume Muñoz Conde (Ibidem): ‘Em suma, a 'razão de Estado', que é o que monopoliza o poder punitivo ou a funcionalidade de seu sistema, independentemente do que seja democrático ou autoritário, se converte no único fundamento do Direito penal". Nos dá a impressão - permitam-nos uma ingênua ironia - que a democracia é só retórica e realmente não interessa. Aristóteles já preconizava que o grande defeito da democracia é a demagogia. Ao final é só um termo vazio de conteúdo, pura palavra sem um significa prático: democracia para alguns e tortura para outros. Trata-se de uma fina camada de verniz que protege os sistemas que adotam um direito penal preconceituoso e que aplica um punitivismo inconstitucional e seletivo.

\section{A crítica do conceito de não-pessoa: uma forte crítica à negação do fundamento dos direitos humanos}

O professor Lima Torrado (2009, p. 383-384) faz questão de criticar os autores que foram amenos e que parecem relativizar a gravidade do conceito de não-pessoa de Günther Jakobs. Faz a crítica a Silva Sanchéz (2002) quando este minimiza os efeitos do Direito penal do inimigo, e a Schünemann que, citados por Cancio Meliá (2007, p. 60-65), argumenta a partir da já célebre defesa do conceito de Jakobs afirmando que em nenhum caso o Direito penal do inimigo contém uma crua desumanização como nos sistemas opressores racistas ou religiosos, nos quais os afetados pela discriminação não têm direito à vida. Retórica vazia, puras palavras, diz nosso autor homenageado, aos quais não está de acordo quando argumenta 
que os mesmos textos de Jakobs são suficientes explícitos para impugnar as afirmações de seus comentaristas defensores. Para Lima Torrado (2009, p. 384) a negação do conceito de pessoa não implica somente a negação de persona no sentido jurídico, uma vez que é somente em sentido normativo que seus defensores fazem referência. A negação do conceito de pessoa implica também o sentido antropológico da condição de ser humano, diz Lima Torrado (2009 $a$, p. 385). O que nos faz lembrar a famosa controvérsia de Valladollid entre Ginés Sepúlveda e Bartolomé de Las Casas sobre a condição humana dos índios americanos (exatamente a condição de pessoa defendida por Las Casas e a condição de não-pessoa - animal sem alma defendida por Ginés). A negação da juridicidade de uma pessoa não é justificada racionalmente aceitável, não há nenhuma explicação racional nas palavras de Lima Torrado. A critica vai também aos discípulos de Jakobs que justificam sem êxito a negação de uma condição de cidadania aos excluídos, negam o sujeito social, sua condição de humanidade e sua dignidade. Insiste Lima Torrado (2009, p. 384) que, ademais de se tratar de um pessimismo antropológico baseado em Hobbes, significa um perigo para os direitos humanos já que com sua metodologia reducionista, atua como flexibilização do sistema de garantias, e permite a suspensões e a negações de garantias de direitos fundamentais. Assim, nesse sentido, diz Lima Torrado (2009, p. 385):

Al negar el concepto de persona se niega el fundamento de los derechos y al negar el fundamento se niegan los derechos, y al negar los derechos, logicamente, se niegan las garantias: no hay nada que garantizar si no hay sujeto de derechos ni, por tanto los mismo derechos.

Assim seja: ao negar o conceito de pessoa negam-se ao sujeito todos os seus Direitos Humanos e garantias fundamentais, inerentes à sua condição humana e consequentemente os fundamentos dos mesmos direitos que são radicalmente suprimidos porque não se sustentam os pilares que servem de fundamentos ao Estado Social e Democrático de Direito. Nem mesmo a Constituição é aplicada e nem mesmo a legislação internacional de Direitos Humanos. Não sobra nada, apenas a justificativa em nome da segurança do Estado. Essa falsificação do direito já foi vista na história recente de nossos povos e chama-se doutrina da segurança nacional ${ }^{18}$. Não existe nada além de uma falsificação de conceitos, na qual não há nenhum tipo de garantias nem tolerância nem presunção de inocência.

\footnotetext{
${ }^{18}$ Como já foi citado anteriormente, e como também comparam Zaffaroni (2011, p. 50-51) e Lima Torrado (2009 a, p. 387).
} 
Importante ressaltar em suas considerações finais que Lima Torrado (2009, p. 389) afirma que o conceito de não-pessoa é: $1^{\circ}$ ) uma abstração extraordinariamente pobre; $2^{\circ}$ ) um falso conceito (pseudoconceito) jurídico, vazio de conteúdo; assim como $3^{\circ}$ ) um falso conceito que carece de toda conexão sistemática com os princípios, valores e normas próprios de um Estado Democrático de Direito (que é o que deveria legitimar todo o sistema); $4^{\circ}$ ) uma nova expressão do irracionalismo atual, também importante frisar que o conceito de nãopessoa pretende ganhar terreno diante dos direitos humanos; $5^{\circ}$ ) uma tentativa de concreção do pensamento único que a globalização neoliberal pretende em sua dimensão ideológica (Lima Torrado, 2009 b); 6º uma manifestação e instrumento ideológico-político-jurídico de um novo totalitarismo que pretende corroer o sistema de Direitos Humanos. E que segundo Lima Torrado, infelizmente, em parte está conseguindo romper com o sistema de Direitos Humanos.

Ademais segundo o professor da Universidade Complutense (2009, p. 389) as teses de Jakobs negam todos e cada um dos elementos que compõe estruturalmente o sistema de Direitos Humanos; o pensamento de Jakobs, ainda que aparentemente tenha uma motivação asseguradora de vantagens para a Sociedade, entre em franca colisão com um sistema garantista dos direitos fundamentais. Ainda, por conseguinte destaca-se que alude o professor Lima Torrado que as teses de Jakobs supõe uma falsa legitimação (pseudolegitimação) de um chamado Direito penal do inimigo e de umas estruturas jurídico-políticas que sustentam graves violações dos Direitos Humanos, assim como sustentam a negação das garantias institucionais internas e internacionais dos mesmos e são a afirmação de um Estado autocrático e arbitrário. Para o professor Jesus Lima Torrado a possibilidade de supressão das garantias processuais, acrescenta-se que são conquistas humanas civilizatórias, em sua opinião são a negação dos valores que sustentam e legitimam os direitos fundamentais e em especial a dignidade da pessoa humana. Trata-se, pois, nas palavras de Lima Torrado de uma concepção totalitária do Direito e do Estado quando se nega a essencial unidade existente entre o fundamento e as garantias dos Direitos Humanos.

Por fim, Lima Torrado (2009, p. 390) advoga por uma Teoria Crítica dos Direitos Humanos que deve: analisar, desmascarar e denunciar as formas de irracionalidade existentes nas formulações doutrinais que sustentam sistemas jurídicos particularmente arbitrários e desiguais. Desiguais e preconceituosos quando os mesmos insistem e reiteram o uso do conceito da não-pessoa, ou seja, a existência de um ser humano que não é titular da dignidade 
da pessoa humana. Assim, mediante a construção de uma crítica à doutrina excludente de direitos, a Teoria dos Direitos Humanos deveria consolidar-se como uma fundamentação de garantia dos direitos, enquanto instrumento dialético a favor de uma educação em direitos humanos.

\section{Considerações Finais}

O Direito penal do inimigo nem Direito penal deve ser considerado, nas palavras de Muñoz Conde, como foi visto, já que seu conceito é um falso conceito, segundo palavras de Lima Torrado. E segundo alguns diversos juristas críticos, entre eles Zaffaroni, Muñoz Conde e Lima Torrado, o direito penal do inimigo atenta e viola diretamente o Estado Democrático de Direito. Ademais a negação da dignidade da pessoa humana, as garantias de direitos fundamentais, e o falso conceito de não-pessoa, todos dirigidos à figura do "inimigo", segundo Lima Torrado, abrem a porta para sistemáticas violações de Direitos Humanos.

A gravidade do assunto é que cada vez mais os Estados estão aderindo à prática do pseudodireito penal do inimigo. Sejam por desculpas como o terrorismo, a segurança do Estado, a eliminação de adversários políticos e motivos sociais como a aporofóbia, classismo, racismo, xenofobismo e outras mazelas de nossa era.

Não cabe dúvidas que a aplicação do conceito de não-pessoa nos remete a dois momentos importantes da história relacionados com a América e Espanha: $1^{\circ}$ ) durante a chamada controvérsia de Valladolid. Quando o frei Bartolomé de Las Casas fez a sua defesa da condição de pessoa, de ser humano racional do índio americano ante o dominicano Juan Ginés Sepúlveda em 1550-1551; $2^{\circ}$ ) durante as ditaduras franquistas e as ditaduras da América Latina. Violavam-se os Direitos Humanos em nome da segurança do Estado. A doutrina da segurança natural, típica da guerra fria e com as mesmas origens do nazismo, foi aplica nos países da América com o terrorismo de Estado em nome da segurança nacional e contra o inimigo subversivo que não tinha nenhum Direito e era arbitrariamente assassinado.

O Estado democrático de Direito, sem dúvida, é - desde sua cláusula de igualdade formal (todos são iguais perante a lei) e de igualdade material (democracia substancial) profanado, violado, uma vez que seus conceitos mais básicos foram relativizados e resinificados pela teoria do Direito penal do inimigo: foram profanadas as liberdades, as garantias penais, a igualdade assim como a dignidade da pessoa humana. A palavra profanado, desde um estado cotidiano de exceção, se deve aqui as ideias de Agamben (2007). 
Para finalizar a resposta é não. Não se pode negar a dignidade de um ser humana. Com claridade e evidentemente que são característica de regimes autoritários: praticar a tortura, negar a dignidade de um ser humano, negar sua condição de pessoa, negar suas garantias fundamentais e seus direitos fundamentais. Tais questões não são compatíveis com um autêntico Estado Democrático de Direito.

\section{Referências:}

AGAMBEN, Giorgio. Estado de Exceção. Tradução de Iraci D. Poleti. São Paulo: Boitempo, 2004.

AGAMBEN, Giorgio. Profanações. Tradução e apresentação de Selvino José Assman. São Paulo: Boitempo, 2007.

BAUMAN, Zygmunt. Vidas desperdiçadas. Tradução de Carlos Alberto Medeiros. Rio de Janeiro: Zahar, 2005.

BAUMAN, Zygmunt. Vida para consumo: a transformação das pessoas em mercadorias. Tradução de Carlos Alberto Medeiros. Rio de Janeiro: Zahar, 2008.

BECK, Ulrich. Sociedade de risco: rumo a uma outra modernidade. São Paulo: Editora 34, 2011.

BOBBIO, Norberto. Presente e futuro dos direitos do homem. In: A era dos Direitos. Tradução de Carlos Nelson Coutinho. Rio de Janeiro: Campus, 1992. p. 25-47

BONAVIDES, Paulo. Curso de Direito Constitucional. 29.ed. São Paulo: Malheiros, 2014.

CANCIO MELIÁ, Manuel. "Direito Penal" do inimigo? In: Jabobs, Günter; CANCIO MELIÁ, Manuel. Direito Penal do Inimigo: noções e críticas. Org. e Trad. De André Luís Callegari e Nereu José Giacomelli. 2ed. Porto Alegre: Livraria do Advogado, 2007. p. 51-80.

CASTELLS, Manuel. Redes de indignación y esperanza. Madrid: Alianza Editorial, 2012.

CHOMSKY, Noan. Quem manda no mundo? Tradução Renato Marques. São Paulo: Crítica, 2017.

COMBLIN, Joseph. A Ideologia da Segurança Nacional: O Poder Militar na América Latina, 2.ed., Rio de Janeiro: Ed. Civilização Brasileira, 1978.

FERRAJOLI, Luigi. Derechos y garantías: la Ley del más débil. Madrid: Trotta, 1999.

FERRAJOLI, Luigi. Democracia y garantismo. Tradução de Perfecto A. Ibáñez, et. al. Madrid: Trotta, 2008. FERRAJOLI, Luigi. Derecho y razón. Tradução Perfecto Andrés Ibáñez. 7.ed. Madrid: Trotta, 2005. Título original: Diritto e ragione.

FERRAJOLI, Luigi. Poderes salvajes: la crisis de la democracia constitucional. 2.ed. Tradução de Perfecto A. Ibáñez. Madrid: Trotta, 2011.

HAYEK, Friedrich August von. O caminho da servidão. Trad. de Ana M. Capovilla. São Paulo: Editora Liberal, 1990.

GIDDENS, Antony. Mundo em descontrole: o que a globalização está fazendo de nós. Tradução de Maria Luiza Borges. Rio de Janeiro: Editora Recorde, 2003.

GONZÁLEZ AMUCHASTEGUI, Jesus. Autonomía, dignidade y ciudadanía: una teoria de los derechos humanos. Valencia: Tirant lo Blanch, 2004.

KANT, Immanuel. Fundamentação da Metafísica dos Costumes. In: Os Pensadores - Kant (II). Tradução de Paulo Quintanela. 2.ed. São Paulo: Abril Cultural, 1984. p. 103-162. Título original: Grundlegung zur Metaphysik der Sitten.

LASSALLE, Ferdinand. A essência da Constituição. 4. ed. Rio de Janeiro: Lumes Juris, 1998.

LIMA TORRADO, Jesus. El pseudoconcepto de no-persona: de la negación del fundamento de los derechos humanos a la justicación de la negación de las garantías. Revista de Ciências Jurídicas e Sociais. UNIPAR. Umuarama. v. 12, n. 2, p. 377-396, jul./dez. 2009.

LIMA TORRADO, Jesus. Globalización, pensamiento único y derechos humanos: análisis desde una teoría crítica del derecho. In: LIMA TORRADO, Jesus (Coord.) Derechos, Estado, Mercado: Europa y América Latina. Madrid: Dilex, 2009. p. 165-193.

LIMA TORRADO, Jesus. Fundamentos de los Derechos Humanos. Revista do Programa de Mestrado em Ciência Jurídica. Universidade Estadual do Norte do Paraná - UENP. Jacarezinho. n. 16, p. 223-246, jan./jul. 2012.

MARSHALL, Thomas H. Ciudadanía y clase social. Tradução de Pepa Linares. Madrid: Alianza, 1998. 
MERQUIOR, José Guilherme. O liberalismo: antigo e moderno. Tradução de Henrique Araújo Mesquita. 3.ed. São Paulo: É Realizações Editora, 2014.

MORIN, Edgar. A via para o futuro da humanidade. São Paulo: Bertrand, 2013.

MÜLLER, Friedrich. Que grau de exclusão social ainda pode ser tolerado por um sistema democrático? Tradução de Peter Naumann. Porto Alegre: Unidade Editorial da Secretaria Municipal da Cultura, 2000.

MUÑOZ CONDE, Francisco. Direito penal do inimigo. Tradução de Karyna Batista Sposato. Curitiba: Juruá, 2012.

NEVES, Marcelo. A Constitucionalização Simbólica. São Paulo: Martins Fontes, 2007.

PASOLD, Cesar Luiz. Metodologia da pesquisa jurídica: teoria e prática. 14. ed. Florianópolis: Empório Modara, 2018.

PECES-BARBA, Gregorio. La dignidade de la persona humana desde la Filosofía del Derecho. 2. Ed. Madrid: Dykinson, 2003.

PECES-BARBA, Gregorio. Problemas generales. In: general. Madrid: Universidad Carlos III de Madrid, 1995. p. 39-98.

PECES-BARBA, Gregorio. La libertad del hombre y el genoma. Derechos y Libertad. Revista del Instituto Bartolomé de las Casas. N. 2, año I, Universidad Carlos III de Madrid. p. 302-325. Oct. 1993-Mar 1994.

PÉREZ LUÑO, Antonio Enrique. Derechos Humanos, Estado de Derecho y Constitución. 2.ed. Madrid: Tecnos, 1986.

ROSA, Halmut. Alienación y aceleración: hacía uma teoria crítica de la temporalidade en la modernidad tardía. Tradução, revisão e notas de Estefanía Dávila e Maya Aguiluz Ibargüen. Madrid: Katz, 2016.

SALES I CAMPOS, Albert. El delito de ser pobre: una gestión neoliberal de la marginalidade. Barcelona: Icara, 2014.

SANTOS, Boaventura de Sousa. Para uma revolução democrática da justiça. 3 ed. São Paulo: Cortez, 2011.

SARLET, Ingo Wolfgang. Dignidade da Pessoa Humana e Direitos Fundamentais. Porto Alegre: Livraria do Advogado, 2001.

SARMENTO, Daniel. Dignidade da pessoa humana: conteúdo, trajetórias e metodologia. Belo Horizonte: Fórum, 2016.

SILVA SÁNCHEZ. Jesus Maria. A expansão do Direito Penal. São Paulo: Revista dos Tribunais, 2002.

SOUZA, Jessé. A elite do atraso: da escravidão à lava jato. Rio de Janeiro: Leya, 2017.

SOUZA, Jessé. A tolice da inteligência brasileira: ou como o país se deixa manipular pela elite. Rio de Janeiro: Leya, 2015.

SOUZA, Jessé. Senso comum e justificação da desigualdade. In: A ralé brasileira: quem é e como vive. 3.ed. São Paulo: Contracorrente, 2018 a. p. 47-55.

SOUZA, Jessé. Subcidadania brasileira: para entender o país além do jeitinho brasileiro. Rio de Janeiro: Leya, $2018 b$.

STRECK, Lênio Luiz: SANTOS JÚNIOR. Rosivaldo Toscano. Do direito penal do inimigo ao direito penal do amigo do poder. Revista de Estudos Criminais, n. 51. p. 33-60. Out./Dez. 2013.

ZAFFARONI, Eugenio Raúl. La pachamama y el humano. Buenos Aires: Ediciones Madres de la Plaza de Mayo/Colihue, 2015.

ZAFFARONI, Eugenio Raúl. O inimigo no direito penal. Tradução de Sérgio Lamarão. 3. Ed. Rio de Janeiro: Renavan, 2011.

ZIZEK, Slavoj. Primero como tragédia, despois como farsa. Tradução Maria B. de Medina. São Paulo: Boitempo, 2011. 